\title{
Survival analysis for success of Molteno tube implants
}

\author{
D C Broadway, M Iester, M Schulzer, G R Douglas
}

\begin{abstract}
Aim-To apply survival analysis in assessing the long term outcome of Molteno tube implantation and to identify risk factors for failure.

Methods-A retrospective, 10 year, consecutive case series study of 119 eyes that underwent implantation of a Molteno tube. The main outcome measures considered were intraocular pressure (IOP), visual acuity, and complications.

Results-A $30 \%$ or greater reduction in IOP was achieved in $68.9 \%$ of cases. However, the overall, "complete success" rate (IOP $<22 \mathrm{~mm} \mathrm{Hg}$ with no medications) after a mean (SD) follow up period of 43 (33) months (range 6-120) was only $33.6 \%$ despite a fall in mean (SD) IOP from 38.2 (8.2) $\mathrm{mm} \mathrm{Hg}$ to 20.1 (11.0) $\mathrm{mm} \mathrm{Hg}$. The "qualified success" rate (IOP $<22 \mathrm{~mm} \mathrm{Hg}$ with or without medications) was $60.5 \%$. Failure was most common in the first postoperative year but could occur after several years, the survival curve having an exponential shape. The only statistically significant risk factor for failure identified was pseudophakia, although eyes with neovascular glaucoma tended to fare poorly. Postoperative IOP tended to be lower after double plate than after single plate implantation. There was no significant difference in outcome based on age, sex, race, previous penetrating keratoplasty, or previous conjunctival surgery. Conclusions-In eyes at high risk of trabeculectomy failure, implantation of an aqueous shunt device should be considered. Pseudophakia should be considered an additional risk factor for failure. Early failure appeared relatively more common but long term follow up of all cases is recommended to ensure adequate management of late failures.

(Br F Ophthalmol 2001;85:689-695)
\end{abstract}

Despite the introduction of other treatment methods with potential advantages over tube implantation, none are fully accepted worldwide and many clinicians continue to implant aqueous shunts for refractory glaucoma. ${ }^{12}$ However, there have been few reports of the long term results in a large series of patients who have undergone tube implantation. The aim of this study was to use survival analyses to evaluate the long term outcome of a large series of implanted Molteno tubes in a single Canadian practice.

\section{Patients and methods}

The outcome of 119 consecutive, single phase, first Molteno tube implantation procedures performed over 10 years (1986-96) in 119 eyes of 119 patients was determined. Patients underwent surgery either for intractable glaucoma, uncontrolled with maximal medical treatment, laser trabeculoplasty and, usually, failed trabeculectomy, or as a primary surgical procedure in patients considered to be at high risk of failure of trabeculectomy with adjunctive antimetabolite treatment.

\section{DATA ANALYSED}

Only 119 cases who had undergone a first single phase implantation technique without antimetabolite augmentation and who were followed up for at least 6 months were included in the analysis. With bilateral surgery, only the first procedure was included. Patient data recorded included age, sex, diagnosis, number and type of previous surgical procedures, visual acuity, the highest previously recorded intraocular pressure (IOP), and the mean of the three most recently recorded preoperative IOP values ("mean preoperative IOP”). Postoperative data included visual acuity at 6 months, IOP after follow up periods of 1 week, 1, 2, 3 and 6 months and 1,2, 3, 5 and 10 years when applicable. In addition, data obtained at the patient's last clinic visit were recorded. The status of the eye with particular respect to treatment (number and type) and complications, was recorded for each visit. All referring ophthalmologists were contacted to contribute missing information.

\section{SURGICAL TECHNIQUE}

A $90^{\circ}$ (single plate implants) or $180^{\circ}$ (double plate implants) superior conjunctival peritomy was performed, the superior rectus isolated, and one (single plate) or both quadrants (double plate) of the superior subconjunctival space cleared. A single plate implant was inserted in eyes with suspected impaired aqueous production or reduced orbital space. The tube was occluded by a $6 / 0$ Vicryl suture and the plate(s) of the device sutured to sclera in the appropriate quadrant(s) with $6 / 0$ silk, positioning the plate(s) $10 \mathrm{~mm}$ posterior to the limbus. With double plate implants the interplate connecting tube was placed beneath the superior 
Table 1 Patient demographic data

\begin{tabular}{|c|c|c|c|c|c|c|c|}
\hline Diagnosis & $\begin{array}{l}\text { No of } \\
\text { eyes }\end{array}$ & $\begin{array}{l}\text { Mean (SD) } \\
\text { age (years) }\end{array}$ & $\begin{array}{l}\text { Sex } \\
(M: F, \%)\end{array}$ & $\begin{array}{l}\text { Race } \\
(W: O, \%)\end{array}$ & $\begin{array}{l}\text { Eye } \\
(R: L, \%)\end{array}$ & $\begin{array}{l}\text { Implant } \\
(S: D, \%)\end{array}$ & $\begin{array}{l}\text { Mean (SD) } \\
\text { follow up } \\
\text { (months) }\end{array}$ \\
\hline All patients & 119 & $46(27)$ & $47: 53$ & $87: 13$ & $50: 50$ & $25: 75$ & $43(33)$ \\
\hline 1 Developmental & 38 & $21(20)$ & $47: 53$ & $90: 10$ & $42: 58$ & $18: 82$ & $50(34)$ \\
\hline $2 \mathrm{POAG}$ & 13 & $73(10)$ & $23: 77^{\star}$ & $85: 15$ & $54: 46$ & $8: 92$ & $55(33)$ \\
\hline $3 \mathrm{CCAG}$ & 10 & $62(15)$ & $70: 30$ & $90: 10$ & $70: 30$ & $10: 90$ & $54(34)$ \\
\hline 4 Uveitic & 19 & $54(22)$ & $47: 53$ & $90: 10$ & $53: 47$ & $32: 68$ & $45(39)$ \\
\hline 5 Traumatic & 15 & $36(18)$ & $67: 33 \dagger$ & $60: 40 \ddagger$ & $33: 67$ & $13: 87$ & $33(29)$ \\
\hline 6 Neovascular & 19 & $66(21)$ & $47: 53$ & $95: 5$ & $53: 47$ & $58: 42$ - & $28(25)$ \\
\hline 7 Miscellaneous & 5 & $59(24)$ & $0: 100$ & $100: 0$ & $80: 20$ & $40: 60$ & $10(7)$ \\
\hline \multicolumn{8}{|l|}{ Statistics: } \\
\hline \multicolumn{2}{|l|}{$\chi^{2} /$ Fisher's test } & & $\begin{array}{l}{ }^{\star} \mathrm{p}=0.06 \\
\mathrm{tp}=0.09\end{array}$ & $\neq \mathrm{p}=0.001$ & NS & $\uparrow \mathrm{p}=0.0003$ & \\
\hline \multirow{4}{*}{$\begin{array}{l}\text { ANOVA } \\
\text { Duncan's }(\mathrm{p}<0.05)\end{array}$} & & $\mathrm{p}<0.00001$ & & & & & $\mathrm{p}=0.02$ \\
\hline & & $1<2-7$ & & & & & $6<1,2$ \\
\hline & & $5<2-4,6,7$ & & & & & $7<1-3$ \\
\hline & & $2>1,4,5$ & & & & & \\
\hline
\end{tabular}

$\mathrm{SD}$ = standard deviation; $\mathrm{M}: \mathrm{F}$ = male:female; $\mathrm{W}: \mathrm{O}=$ White:Oriental; $\mathrm{R}: \mathrm{L}$ = right:left; $\mathrm{S}: \mathrm{D}=$ single:double; POAG = primary open angle glaucoma; $\mathrm{CCAG}=$ chronic closed angle glaucoma; $\mathrm{NS}=$ not significant.

*Most patients with POAG were female.

†Most patients with traumatic glaucoma were male.

‡Compared with other diagnoses, traumatic glaucoma was more common in eyes of non-white patients

TSingle plate implants were more commonly inserted in eyes with neovascular glaucoma, compared with other diagnoses.

rectus. A radial scleral groove was fashioned with blade and cautery. Entry into the aqueous chamber was achieved with a 22 gauge needle on a syringe containing sodium hyaluronate, some of which was injected into the chamber before the appropriately trimmed tube was inserted. The extraocular portion of the tube was sutured into the scleral groove and covered with a scleral patch graft using $8 / 0$ Vicryl. The conjunctival flap was closed with $8 / 0$ Vicryl and subconjunctival antibiotic/steroid was administered. A topical antibiotic was prescribed for 1 month postoperatively and steroid for up to 3 months.

DEFINITIONS OF SUCCESS/FAILURE

"Complete success": IOP 6-22 mm Hg without antiglaucoma medication.

"Partial success": IOP 6-22 $\mathrm{mm} \mathrm{Hg}$ with medication at the time of the last visit.

"Qualified success": combination of "complete" and "partial" success.

"Partial failure": IOP >21 mm Hg despite additional medications.

"Complete failure": loss of light perception, the requirement of a cyclo-destructive procedure, or further glaucoma surgery.

Eyes with an IOP of $<6 \mathrm{~mm} \mathrm{Hg}$ with no loss of best corrected visual acuity were included as successes. In addition, success was defined on the basis of achieving a "target IOP" of at least a $30 \%$ reduction (from the mean of the three most recent preoperative IOP measurements) with either no or reduced anti-glaucomatous treatment.

Visual field changes and transient IOP spikes were ignored in defining success.

\section{STATISTICS}

Group comparisons were made using a $t$ test, an analysis of variance for continuous data (ANOVA with Duncan's correction), and Pearson's $\chi^{2}$ or Fisher's exact test (when expected cell value was $<5$ ) for categorical data. The Wilcoxon matched pairs signed rank test was used to compare differences between mean IOP values. Kaplan-Meier survival curves were drawn using each definition of

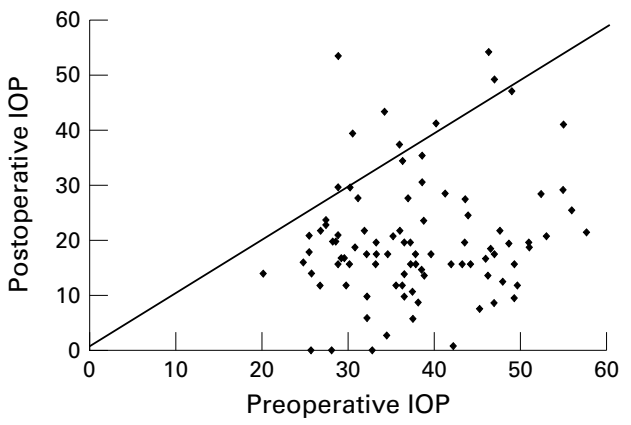

Figure 1 Scatter plot of mean preoperative intraocular pressure (IOP) against final postoperative IOP for all eyes. Some points overlie others and may represent more than one case. The oblique line of no change in IOP is drawn to show that there was a reduction in IOP for the majority of cases.

success. Curves were constructed for the whole group and for risk factor subgroups, differences in success being compared using the log rank test. A Cox multivariate analysis was performed to investigate the effect of certain continuous variables. A $p$ value of $\leqslant 0.05$ was considered significant.

\section{Results}

Demographic data for all patients are given in Table 1 . The mean age was 46 years, mean follow up was 43 months, and most of the patients were white, making assessment of racial factors unreliable. The mean preoperative IOP (38.2 $\mathrm{mm} \mathrm{Hg}$ ) was reduced in $92.4 \%$ of cases by the end of the follow up period to achieve a mean IOP of $20.1 \mathrm{~mm} \mathrm{Hg}$ (Fig 1).

Overall, "complete success" was $34 \%$ although "qualified success" was significantly greater at $60.5 \%$. A $30 \%$ or greater reduction in IOP was achieved in $68.9 \%$ with a fall from the highest mean (SD) preoperative IOP of 46.3 (9.8) $\mathrm{mm} \mathrm{Hg}$ to 20.1 (11.0) $\mathrm{mm} \mathrm{Hg}$. The Kaplan-Meier survival plots for all eyes are shown in Figure 2. The IOP profile with time for the whole group is shown in Figure 3.

\section{GLAUCOMA DIAGNOSIS}

There were significant demographic differences between the diagnostic groups (Table 1), but a reduction in IOP occurred in all (Table 


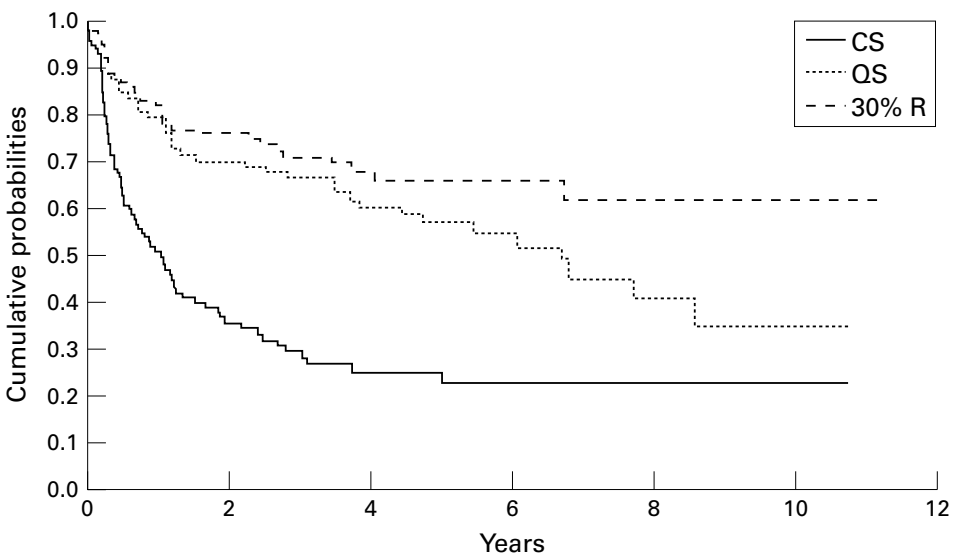

Figure 2 Kaplan-Meier survival curves for all patients, plotting the cumulative probabilities against time that (i) the intraocular pressure (IOP) remains below $22 \mathrm{~mm} \mathrm{Hg}$ without additional medical treatment ("complete" success: CS), (ii) the IOP remains below $22 \mathrm{~mm} \mathrm{Hg}$ with or without additional medical treatment ("qualified" success: QS); and (iii) the IOP remains below the target IOP (set as a $30 \%$ reduction from the mean preoperative IOP; $-30 \% R$ ) following tube implantation.

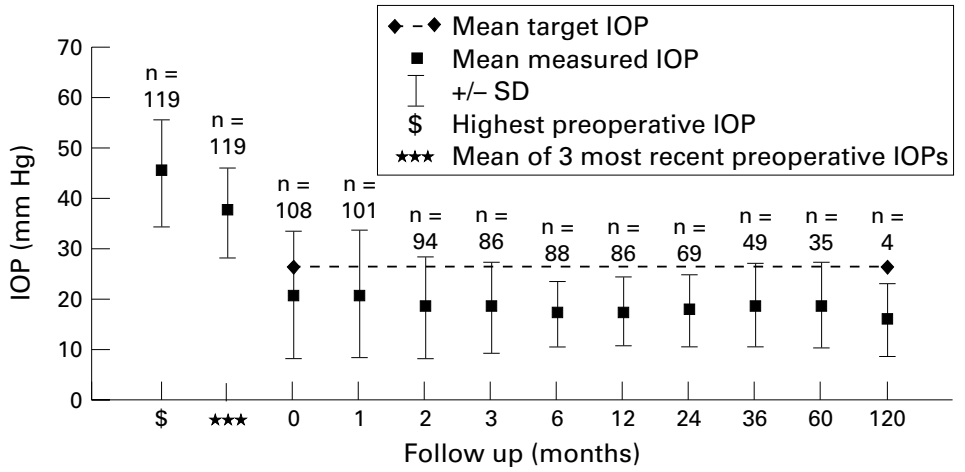

Figure 3 Intraocular pressure (IOP) versus time profile for the whole patient group. The first point represents the highest recorded preoperative IOP levels and the second point the mean of the three most recent preoperative IOP values. The other points represent the mean IOP values for the appropriate postoperative time point.

Table 2 Reduction in intraocular pressure (IOP) by diagnosis

\begin{tabular}{lrllll}
\hline Diagnosis & $n$ & $\begin{array}{l}\text { Mean preop IOP } \\
(\mathrm{mm} \mathrm{Hg})\end{array}$ & $\begin{array}{l}\text { Final postop IOP } \\
(\mathrm{mm} \mathrm{Hg})\end{array}$ & \% reduction & p Value \\
\hline All patients & 119 & $38.2(8.2)$ & $20.1(11.0)$ & 47.4 & 0.00001 \\
Developmental & 38 & $34.9(7.3)$ & $18.6(8.7)$ & 46.7 & 0.00001 \\
POAG & 13 & $36.8(7.5)$ & $20.2(11.6)$ & 45.1 & 0.01 \\
CCAG & 10 & $43.6(5.3)$ & $16.4(13.3)$ & 62.4 & 0.007 \\
Uveitic & 19 & $39.4(9.2)$ & $19.4(9.8)$ & 50.8 & 0.0001 \\
Traumatic & 15 & $39.9(10.0)$ & $22.5(12.7)$ & 43.6 & 0.002 \\
Neovascular & 19 & $39.9(7.1)$ & $24.0(12.1)$ & 39.8 & 0.0003 \\
Miscellaneous & 5 & $40.6(7.9)$ & $19.8(15.5)$ & 51.2 & 0.1 \\
\hline
\end{tabular}

POAG = primary open angle glaucoma $\mathrm{CCAG}=$ chronic closed angle glaucoma . Values are mean (SD).

Table 3 Success rates by diagnosis using differing success criteria

\begin{tabular}{lrlll}
\hline Diagnosis & $n$ & $\begin{array}{l}\text { Complete success } \\
(\%)\end{array}$ & $\begin{array}{l}\text { Qualified success } \\
(\%)\end{array}$ & $\begin{array}{l}\text { Target success } \\
(\%)\end{array}$ \\
\hline All patients & 119 & 33.6 & 60.5 & 68.9 \\
Developmental & 38 & 31.6 & 57.9 & 65.8 \\
POAG & 13 & 30.8 & 69.2 & 76.9 \\
CCAG & 10 & 40.0 & 70.0 & 70.0 \\
Uveitic & 19 & 42.1 & 68.4 & 89.5 \\
Traumatic & 15 & 33.3 & 60.0 & 66.7 \\
Neovascular & 19 & 26.3 & 52.6 & 57.9 \\
Miscellaneous & 5 & 40.0 & 40.0 & 40.0 \\
\hline
\end{tabular}

POAG $=$ primary open angle glaucoma CCAG $=$ chronic closed angle glaucoma; target success $=$ reduction in $\mathrm{IOP}$ of $>30 \%$.

2). The mean percentage reduction in IOP was greatest for eyes with angle closure $(62.4 \%)$ and uveitic glaucoma $(50.8 \%)$ and least for eyes with neovascular $(39.8 \%)$ or traumatic glaucoma (43.6\%). Success rates were different for the various diagnostic groups of patients (Table 3). When considering both "complete" and "qualified" success, the analyses demonstrated relatively higher success rates for patients with chronic closed angle glaucoma (CCAG; $40 \%, 70 \%$ ) and low success for those with neovascular glaucoma $(26.3 \%$, $52.6 \%$ ), but the differences failed to reach statistical significance by survival analysis. Glaucoma diagnosis was, however, a marginal predictor of success $(p=0.05)$ when considering success as a reduction in IOP of at least $30 \%$ (Figure 4 ), the highest success being for eyes with uveitic glaucoma $(89.5 \%)$ or primary open angle glaucoma (POAG; 76.9\%) and the lowest for eyes with neovascular glaucoma $(57.9 \%)$.

AGE GROUP

There were significant demographic differences between the age groups (Table 4). Survival analysis revealed a statistically significant difference $(p=0.02)$ between the results when considering "complete success" (Fig 5), being worse for patients aged 31-60 years. However, age had no significant effect on outcome in any other analysis.

\section{SINGLE PLATE VERSUS DOUBLE PLATE TUBE}

IMPLANTATION

Most eyes had double plate rather than single plate tubes implanted. "Complete success" was achieved in $36.0 \%$ of eyes with a double plate and "qualified success" in $60.7 \%$ with a fall in IOP of $46.9 \%$ (from 39.0 (8.7) $\mathrm{mm} \mathrm{Hg}$ to 20.7 $(11.8) \mathrm{mm} \mathrm{Hg}$ ), the target IOP being achieved in $70.8 \%$ of eyes. The success rate in eyes with a single plate implant was similar, "complete success" being lower at $26.7 \%$ and "qualified success" being similar at $60 \%$; the mean reduction in IOP was higher at $49 \%$ (from 35.9 (5.6) $\mathrm{mm} \mathrm{Hg}$ to 18.3 (9.1) $\mathrm{mm} \mathrm{Hg}$ ), but with a lower attainment of target IOP (63.3\%). Despite the overall tendency for the double plate to be more effective than the single plate, by survival analysis there was no statistically significant difference (Fig 6).

\section{PREVIOUS OCULAR SURGERY}

Eighty nine of the 119 eyes (74.8\%) had undergone previous surgery involving conjunctival incision, and by survival analysis such surgery had no statistically significant effect on outcome.

Fifty nine of the 119 eyes (49.6\%) had undergone previous glaucoma filtration surgery (GFS). In virtually all the eyes with POAG $(92.3 \%)$ one or more trabeculectomies had been performed, significantly more than for patients with other diagnoses $(p=0.001)$, especially neovascular glaucoma $(10.5 \%$; $\mathrm{p}=0.0002)$. By categorical group analysis, the younger patients had undergone previous GFS less frequently than patients in the older groups $(p=0.007)$, the mean age of those who had undergone GFS being 53 (22) years compared with 39 (31) years for those who had not $(\mathrm{p}=0.001)$. "Complete success" was achieved in $28.8 \%$ of eyes that had undergone previous 


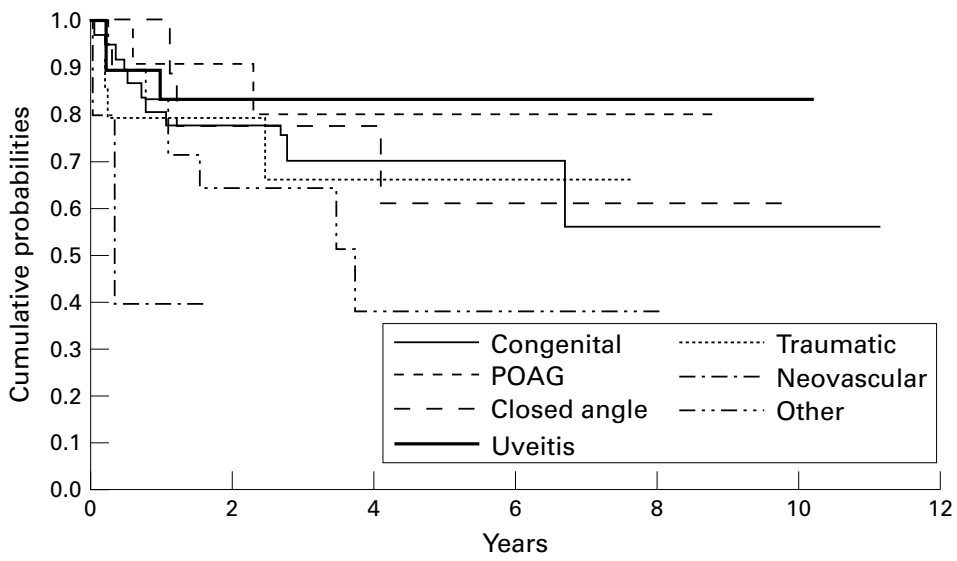

Figure 4 Kaplan-Meier survival curves based on diagnostic category, plotting the cumulative probabilities against time that intraocular pressure (IOP) remains below the target IOP (set as a 30\% reduction from the mean preoperative IOP) following tube implantation. POAG = primary open angle glaucoma .

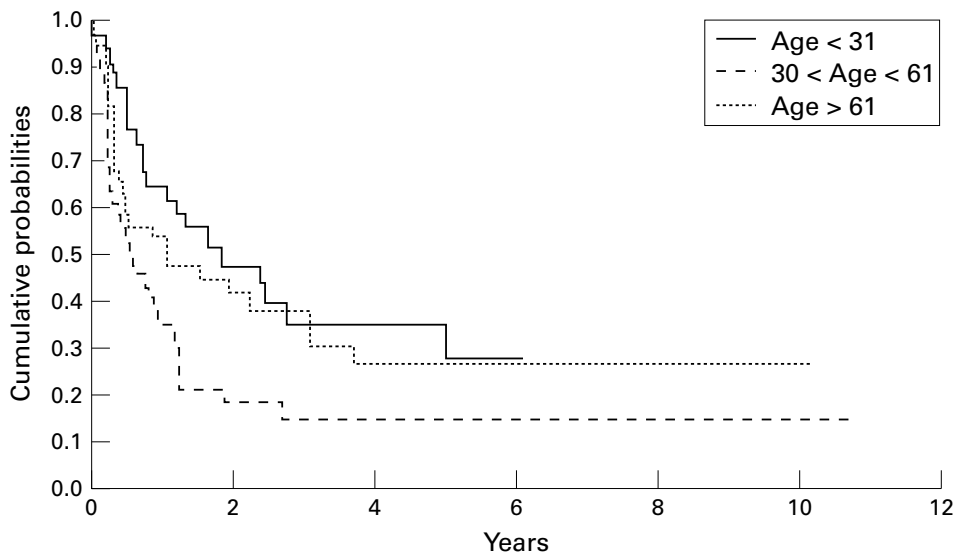

Figure 5 Kaplan-Meier survival curves based on age group (0-30 years, 31-60 years, 61-91 years), plotting the cumulative probabilities against time that intraocular pressure (IOP) remains below $22 \mathrm{~mm} \mathrm{Hg}$ without additional medical treatment ("complete" success) following tube implantation.
GFS, "qualified success" in $57.6 \%$ with a fall in IOP of $46.5 \%$ (from 37.6 (8.5) $\mathrm{mm} \mathrm{Hg}$ to $20.1(11.1) \mathrm{mm} \mathrm{Hg}$ ), and the target IOP was achieved in $66.1 \%$. The results for those that had not undergone GFS, although tending to be better, were not statistically different, the "complete" and "qualified" success rates being higher at $38.3 \%$ and $63.3 \%$, respectively, with the mean reduction in IOP of $48.3 \%$ (from 38.9 (7.9) $\mathrm{mm} \mathrm{Hg}$ to 20.1 (11.0) $\mathrm{mm} \mathrm{Hg}$ ) being similar, and the target IOP being achieved in $71.7 \%$. Survival analysis confirmed these findings (Fig 7) and Cox multivariate analysis showed that the number of previous GFS procedures had no statistically significant effect on outcome.

Only 24 eyes had undergone previous penetrating keratoplasty (PK), mainly in younger patients (33 (25) v 49 (27) years; $\mathrm{p}=0.01)$ with traumatic glaucoma $(46.7 \%)$ or developmental glaucoma (26.3\%). The "complete" and "qualified" success rates for eyes that had undergone PK were $41.7 \%$ and $62.5 \%$, respectively, with a fall in IOP of $55.6 \%$ (from 39.2 (6.8) $\mathrm{mm} \mathrm{Hg}$ to 17.4 (11.8) $\mathrm{mm} \mathrm{Hg}$ ), the target IOP being achieved in $62.5 \%$. The results for those that had not undergone PK were similar ("complete" success $31.6 \%$; "qualified" success $60 \%$; mean reduction in IOP $45.3 \%$ (from 38.0 (8.5) $\mathrm{mm} \mathrm{Hg}$ to 20.8 (10.7) $\mathrm{mm} \mathrm{Hg}$ ), although more achieved the target IOP $(70.5 \%)$. However, survival analysis revealed no effect of previous PK on outcome.

Fifty four of the 119 eyes (45.4\%) were phakic, $35(29.4 \%)$ pseudophakic, and $30(25.2 \%)$ aphakic at the time of tube implantation, large incision cataract surgery having been used. Patients with pseudophakia were significantly older (66 (16) years) than those with phakia (38 (28) years) or aphakic patients (36 (26)

Table 4 Patient data according to age group

\begin{tabular}{|c|c|c|c|c|}
\hline Age group & $\begin{array}{l}0-30 \text { years } \\
(n=36)\end{array}$ & $\begin{array}{l}31-60 \text { years } \\
(n=39)\end{array}$ & $\begin{array}{l}61-91 \text { years } \\
(n=44)\end{array}$ & $p$ Value \\
\hline Mean (SD) age & $10.9(10.1)$ & $46.0(9.0)$ & $74.3(7.7)$ & \\
\hline Sex $(M: F, \%)$ & $39: 61$ & $69: 31$ & $34: 66$ & 0.03 \\
\hline Race (W:O, \%) & $83: 17$ & $80: 20$ & $66: 34$ & 0.04 \\
\hline \multicolumn{5}{|l|}{ Diagnosis $(\%)$} \\
\hline Developmental & 72 & 23 & 7 & $<0.000001$ \\
\hline POAG & 0 & 3 & 27 & 0.00006 \\
\hline CCAG & 0 & 8 & 16 & 0.04 \\
\hline Uveitic & 8 & 23 & 16 & NS \\
\hline Traumatic & 14 & 26 & 0 & 0.002 \\
\hline Neovascular & 3 & 15 & 27 & 0.01 \\
\hline Miscellaneous & 3 & 2 & 7 & NS \\
\hline \multicolumn{5}{|l|}{ Lens status (\%) } \\
\hline Phakic & 61 & 48 & 30 & 0.02 \\
\hline Aphakic & 36 & 26 & 16 & NS \\
\hline Pseudophakic & 3 & 26 & 54 & $<0.000001$ \\
\hline Previous surgery (categorical, \%) & 83 & 87 & 86 & NS \\
\hline Previous GFS (categorical, \%) & 72 & 62 & 57 & 0.007 \\
\hline Previous PK (\%) & 28 & 26 & 9 & NS \\
\hline Conjunctival incision (\%) & 53 & 85 & 84 & 0.0008 \\
\hline Implant (S:D, \%) & $22: 88$ & $15: 85$ & $36: 64$ & NS \\
\hline Mean (SD) follow up (months) & $44.9(26.3)$ & $43.6(38.2)$ & $39.8(34.3)$ & NS \\
\hline Mean (SD) preop IOP $(\mathrm{mm} \mathrm{Hg})$ & $37(8)$ & $39(10)$ & $39(7)$ & NS \\
\hline Mean (SD) highest IOP ( $\mathrm{mm} \mathrm{Hg}$ ) & $43(9)$ & $48(11)$ & $47(9)$ & NS \\
\hline Mean (SD) final IOP $(\mathrm{mm} \mathrm{Hg})$ & $19(9)$ & $22(13)$ & $20(11)$ & NS \\
\hline Reduction in IOP (\%) & 49.5 & 44.9 & 47.9 & NS \\
\hline Complete success rate $(\%)$ & 44.4 & $20.5^{\star}$ & 36.4 & 0.02 \\
\hline Qualified success rate $(\%)$ & 61.1 & 48.7 & 70.5 & NS \\
\hline IOP reduced by $>30 \%(\%)$ & 75.0 & 56.4 & 75.0 & NS \\
\hline
\end{tabular}

$\mathrm{M}: \mathrm{F}=$ male:female $; \mathrm{W}: \mathrm{O}=$ White:Oriental $\mathrm{POAG}=$ primary open angle glaucoma CCAG $=$ chronic closed angle glaucoma GFS = glaucoma filtration surgery; $\mathrm{PK}=$ penetrating keratoplasty; $\mathrm{IOP}=$ intraocular pressure; $\mathrm{S}: \mathrm{D}=$ single:double.

$\star$ By survival analysis complete success was lower for patients aged 31-60 than for patients in the other age groups. 


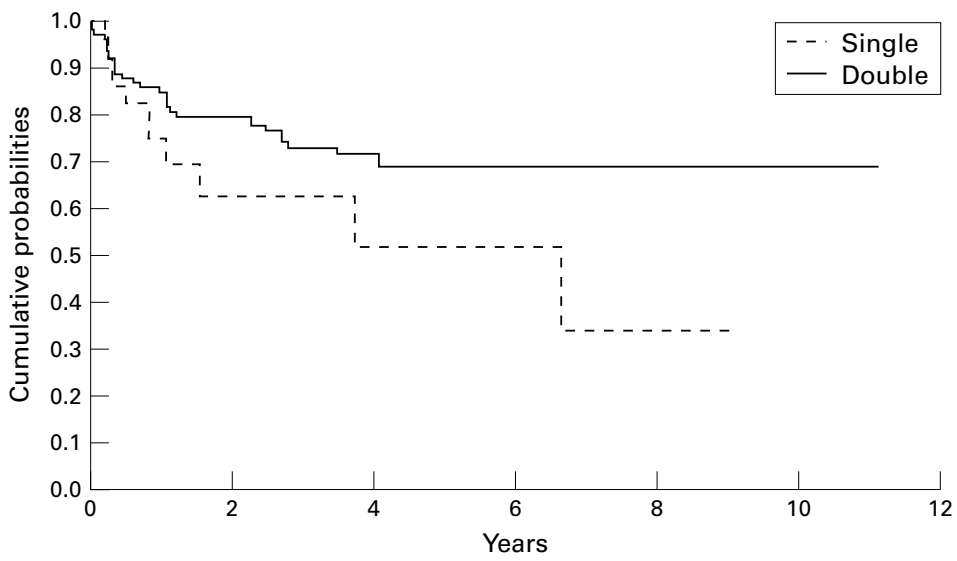

Figure 6 Kaplan-Meier survival curves based on type of Molteno tube implanted (single $v$ double plate), plotting the cumulative probabilities against time that intraocular pressure (IOP) remains below the target IOP (set as a 30\% reduction from the mean preoperative IOP) following tube implantation.

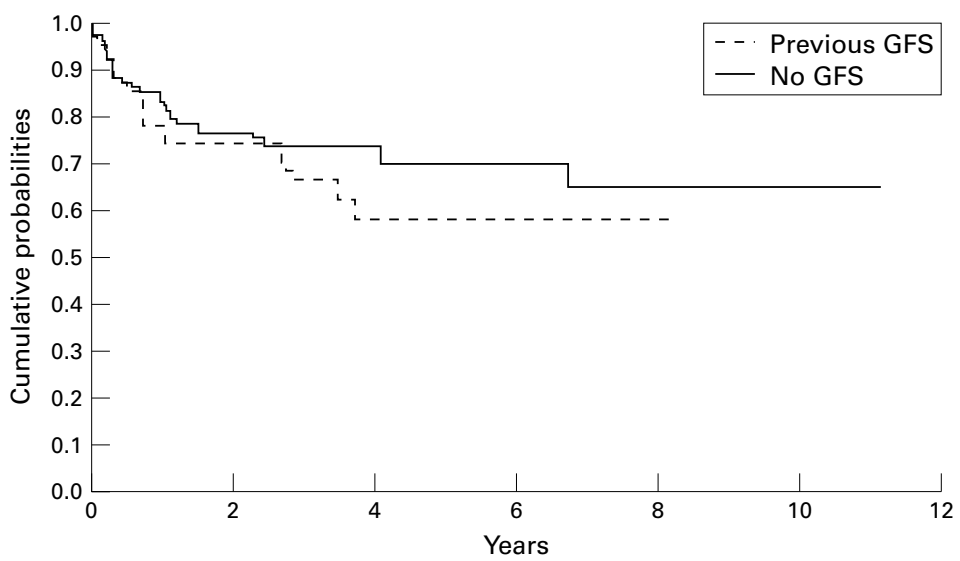

Figure 7 Kaplan-Meier survival curves based on whether or not the eye had undergone previous glaucoma filtration surgery before tube insertion, plotting the cumulative probabilities against time that intraocular pressure (IOP) remains below the target IOP (set as a $30 \%$ reduction from the mean preoperative IOP) following tube implantation.

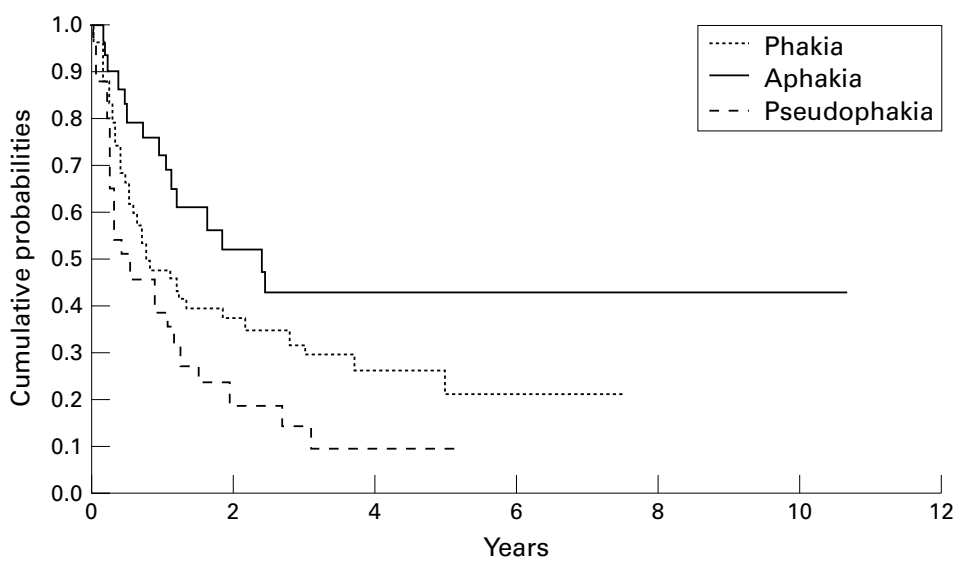

Figure 8 Kaplan-Meier survival curves based on lens status (phakia,pseudophakia, aphakia), plotting the cumulative probabilities against time that intraocular pressure (IOP) remains below $22 \mathrm{~mm} \mathrm{Hg}$ without additional medical treatment ("complete"success) following tube implantation.
Table 5 Complications

\begin{tabular}{lc}
\hline Complication & $n(\%)$ \\
\hline Choroidal effusion & $18(15.1)$ \\
Tube obstruction & $10(8.4)$ \\
Implant extrusion/malposition & $9(7.6)$ \\
Persistent uveitis & $9(7.6)$ \\
Flat anterior chamber & $9(7.6)$ \\
Corneal decompensation & $9(7.6)$ \\
Corneal graft failure & $3(2.5)$ \\
Retinal detachment & $6(5.0)$ \\
Hypotony & $5(4.2)$ \\
Strabismus & $3(2.5)$ \\
Cataract & $3(2.5)$ \\
Significant hyphaema & $1(0.8)$ \\
Choroidal haemorrhage & $1(0.8)$ \\
\hline
\end{tabular}

for pseudophakic eyes there was a tendency for there to be more with uveitic glaucoma $(25.7 \% ; \mathrm{p}=0.06)$ and significantly fewer with developmental glaucoma $(5.7 \% ; \mathrm{p}=0.00007)$; and for aphakic eyes there were significantly more eyes with traumatic glaucoma $(23.3 \%$; $\mathrm{p}=0.04)$ and fewer with neovascular glaucoma $(3.3 \% ; \mathrm{p}=0.03)$. The "complete" and "qualified" success rates for phakic eyes were $31.5 \%$ and $51.9 \%$ with a fall in IOP of $45.9 \%(38.1$ (8.8) $\mathrm{mm} \mathrm{Hg}$ to 20.6 (11.4) $\mathrm{mm} \mathrm{Hg}$ ), the target IOP being achieved in $61.1 \%$. For pseudophakic eyes the results were similar: "complete success" in $20 \%$; "qualified success" in $65.7 \%$; mean reduction in IOP $46.4 \%$ (from 39.0 (7.8) $\mathrm{mm} \mathrm{Hg}$ to 20.9 (11.0) $\mathrm{mm} \mathrm{Hg}$ ), although there was a higher attainment of target IOP $(71.4 \%)$. The success rate was higher for aphakic eyes with "complete success" in $53.3 \%$, "qualified success" in $70 \%$, mean reduction in IOP of $50.9 \%$ (from 37.7 (7.5) $\mathrm{mm} \mathrm{Hg}$ to $18.5(10.4) \mathrm{mm} \mathrm{Hg}$ ), and $80 \%$ attained the target IOP. By survival analysis (Fig 8) "complete success" was significantly greater for aphakic eyes than for pseudophakic eyes $(p=0.002)$, and tended to be greater than the success for phakic eyes $(p=0.06)$. "Complete success" for pseudophakic eyes also tended to be greater than for phakic eyes $(\mathrm{p}=0.06)$. With respect to "qualified success", the rate in aphakic eyes tended to be higher than for phakic eyes $(p=0.07)$.

PREOPERATIVE IOP, SEX, AND RIGHT/LEFT EYE The level of preoperative IOP (mean or highest recorded IOP), sex, and side of procedure had no statistically significant effects on the outcome of tube implantation.

CHANGE IN VISUAL ACUITY AND COMPLICATIONS Visual acuity outcomes, defined as a change of two or more Snellen lines, were improved in $9 \%$, unchanged in $70 \%$, and worse in $21 \%$ at the end of the follow up period. Complications considered to have occurred as a consequence of tube insertion are listed in Table 5.

\section{Discussion}

years; $\mathrm{p}<0.00001)$ and their duration of follow up was significantly less (30.3 (28.1) v 46.8 (30.9) and 49.4 (39.7) months; $\mathrm{p}=0.03$ ).

For phakic eyes there were significantly more with either developmental $(46.3 \% ; \mathrm{p}=0.003)$ or neovascular glaucoma $(24.1 \% ; \mathrm{p}=0.03)$ and fewer with uveitic glaucoma $(5.5 \%$; $=0.005)$;
Although success rates of $90-100 \%$ have been reported following tube implantation, ${ }^{3-5}$ the overall results in the present study were similar to those of most previous studies. ${ }^{3-9}$ However, variation in case selection, diagnostic categorisation, implant type, surgical technique, duration of follow up, and criteria for success in 
previously published studies makes simple comparison inappropriate. Since many patients requiring tubes are young, long term results ${ }^{6}$ and those that have applied survival analysis are of particular interest. ${ }^{7-9}$ After a mean follow up of 30 months, a relatively high "qualified success" rate of $72 \%$ has been reported in a group of 82 black patients with refractory glaucoma and single plate tube implantation. ${ }^{6}$ "Qualified success" rates for the diagnostic groups were $83 \%$ for aphakic/pseudophakic, $80 \%$ for uveitic, $73 \%$ for POAG, $67 \%$ for neovascular, and $50 \%$ for developmental glaucoma. In agreement with the present study and that of Lloyd et al, ${ }^{7}$ therefore, success appeared to be higher in eyes with aphakic glaucoma than in those with various phakic glaucomas. Interestingly, in the present study, by splitting aphakic eyes from pseudophakic eyes, it appeared that pseudophakia was a significant risk factor for tube failure. No obvious compounding factors could be identified to explain this; indeed, the pseudophakic group consisted of older patients and more with uveitic glaucoma, factors more likely to be protective than deleterious. In addition, the results of the present study revealed an increased tendency for failure in eyes with traumatic, developmental and, in particular, neovascular glaucoma, eyes with the latter two diagnoses faring least well in other studies. ${ }^{67}$

Mills and coworkers reported the results of either single or double plate Molteno tube implantation in 77 eyes after a mean follow up of 44 months, comparable with that of the present study. ${ }^{9}$ The overall "qualified success" rate was $57 \%$, similar to our rate of $60.5 \%$. Their group with uveitic glaucoma had the highest "qualified success" rate of $75 \%$, the same as that in our study when attainment of target IOP was considered as the criterion for success. As suggested by other studies, ${ }^{78}$ Mills et al found neovascular glaucoma to be a significant risk factor for failure with an overall "qualified success" rate of $50 \%$, similar to that reported in the present study. ${ }^{9}$ An additional risk factor for failure identified by Mills et al was young age, but only after controlling for diagnostic category. ${ }^{9}$ In the present study no convincing effect of age was identified, although multiple confounding factors may have masked a true effect of age.

The use of single plate tubes versus double plate tubes has been studied by Heuer et $a l^{10}$ who concluded that double plate implantation more frequently afforded IOP control; a similar tendency was found in our study and that of Mills et al. ${ }^{9}$ Since patients were not randomised to the type of implant and selection was based on preoperative factors including IOP, the difference was probably reduced in these studies.

As shown in this study and those of others, ${ }^{7-9}$ "qualified success" showed a steady, almost linear, decline over time whereas the decline occurred in a more exponential manner for "complete success". In considering "complete success", the results are not influenced by the differing degrees and variable timing of additional medical treatment so the pattern of failure can be more readily related to the mechanism of failure. The exponential pattern of failure indicated that, if failure occurred, early loss of IOP control was more common than late failure but there was a continual slow attrition rate for up to at least 4 years after surgery. Since failure is more likely in the first postoperative year than in subsequent years, postoperative management should take this into account and the frequency of postoperative visits should be more frequent in the early postoperative period and less often later on. Furthermore, the propensity for early rather than late failure provides clues as to the mechanism of failure, perhaps indicating that the major cause of early failure is the same as with trabeculectomy-namely, "excessive" wound healing ${ }^{11}$ with a slower wound remodelling process and other factors playing a part in late failure. Histopathological ${ }^{12-19}$ and immunohistochemical ${ }^{19}$ studies indicate that this is likely.

The key factors determining adequate flow and IOP reduction are the resistance of the capsular wall to aqueous flow and the total surface area of encapsulation. ${ }^{20-22}$ Histological studies have supported this by demonstrating that, in comparison with functioning implant blebs, failed blebs have thicker walls made of higher density, relatively hypocellular and avascular connective tissue. Thus, improved results following tube surgery have involved the modulation of early postoperative wound healing with adjunctive mitomycin C. ${ }^{23}$ In a larger study, however, Lee and coworkers ${ }^{25}$ reported no advantage with adjunctive mitomycin C.

Complications of tube surgery are relatively common $^{6-9}{ }^{26-28}$ and there is evidence that the adjunctive use of mitomycin $\mathrm{C}$ increases the rate of complications and, in particular, early postoperative hypotony, ${ }^{25}$ tube blockage,${ }^{24}$ and tube erosion through the conjunctiva. ${ }^{23}$ The authors believe that, in certain eyes thought to be at high risk of tube failure, the use of antiproliferative agents should be considered in a manner similar to the selection of such adjunctive therapy with augmented trabeculectomy. It is probable that, in eyes at particularly high risk of failure, mitomycin $\mathrm{C}$ will offer the best chance of IOP control. Postoperative subconjunctival 5-fluorouracil injections should also be considered in cases where failure appears to be imminent. However, the use of potent agents such as mitomycin $\mathrm{C}$ should be used with caution and the risk:benefit ratio considered before surgery.

In conclusion, this study has shown that, although tube implant surgery is useful in the management of eyes considered to be at high risk of trabeculectomy failure, there is still a significant rate of failure, particularly in the early postoperative period. Pseudophakia was identified as a significant risk factor for failure. Inhibition of early postoperative wound healing with adjunctive antiproliferative agents may help to improve the outcome, and the results of controlled randomised studies are eagerly awaited.

DCB was supported by the Frost Trust, London, UK and the Norwich Glaucoma Research Fund, Norwich, UK and MI was supported in part by the University of Genoa, Italy. 
1 Molteno ACB. New implant for drainage in glaucoma. Clinical trial. Br f Ophthalmol 1969;53:606-15.

2 Assaad MH, Baerveldt G, Rockwood EJ. Glaucoma drainage devices: pros and cons. Curr Opin Ophthalmo

3 Molteno ACB, Polkinghorne J, Bowbyes A. The Vicryl tie technique for inserting a draining implant in the treatmen of secondary glaucoma. Aust NZ F Ophthalmol 1986;14: 343-54.

4 Freedman J. Scleral patch grafts with Molteno setons. Oph thalmic Surg 1987;18:32-4.

5 Omi A, De Almeida GV, Cohen R, et al. Modified Schocket implant for refractory glaucoma. Experience of 55 cases. Ophthalmology 1991;98:211-4.

6 Freedman J, Rubin B. Molteno implants as a treatment for refractory glaucoma in black patients. Arch Ophthalmol 1991;109:1417-20

7 Lloyd MA, Sedlak T, Heuer DK, et al. Clinical experience with the single-plate Molteno implant in complicated glauwith the single-plate Molteno implant in complicated glau679-87.

8 Lavin MJ, Franks WA, Wormald RP, et al. Clinical risk factors for failure in glaucoma tube surgery. A comparison of three tube designs. Arch Ophthalmol 1992,110:480-5.

9 Mills RP, Reynolds A, Emond MJ, et al. Long-term survival of Molteno glaucoma drainage devices. Ophthalmology 1996;103:299-305.

10 Heuer DK, Lloyd MA, Abrams DA, et al. Which is better? One or two? A randomized clinical trial of single-plate versus double-plate Molteno implantation for glaucomas in aphakia and pseudophakia. Ophthalmology 1992;99:15129.

11 Skuta GL, Parrish RK II. Wound healing in glaucoma filtering surgery. Surv Ophthalmol 1987:32:149-70.

12 Folberg R, Hargett NA, Weaver JE, et al. Filtering valve implant for neovascular glaucoma in proliferative diabetic retinopathy. Ophthalmology 1982;89:286-9.

13 Addicks EM, Quigley HA, Green WR, et al. Histologic characteristics of filtering blebs in glaucomatous eyes. Arch characteristics of filtering ble

14 Loeffler KU, Jay JL. Tissue response to aqueous drainage in a functioning Molteno implant. Br f Ophthalmol 1988;72. $29-35$
15 Rubin B, Chan C-C, Burnier M, et al. Histopathologic study of Molteno glaucoma implant in three patients. Am $7 \mathrm{Oph}-$ of Molteno glaucoma im

16 Loeffler KU, Grehn F. Histologischer Vergleich zwischen funktionierender und nicht-funktionierender Filtrationsmembran beim Molteno-Implant. Fortschr Ophthalmol 1990;87:28-31

17 Kramer T, Grossniklaus HE. Molteno implants and operating microscope-induced retinal phototoxicity. Arch Ophthalmol 1991;101:379-83.

18 Lloyd MA, Baerveldt G, Nguyen QH, et al. Long-term histologic studies of the Baerveldt implant in a rabbit model. $\mathcal{F}$ Glaucoma 1996;5:334-9.

19 Classen L, Kivela T, Tarkkanen A. Histopathologic and immunohistochemical analysis of the filtration bleb after unsuccessful glaucoma seton implantation. Am 7 Ophthalmol 1996;122:205-12.

20 Molteno ACB. Use of Molteno implants to treat secondary glaucoma. In: Cairns J, ed. Glaucoma. London: Grune \& glaucoma. In: Cairns J,

21 Rosenberg LF, Krupin T. Implants in glaucoma surgery. In: Ritch R, Shields M, Krupin T, eds. The glaucomas. St Louis: Mosby Year-Book, 1996:1783-807.

22 Prata JA, Mermoud A, LaBree L, et al. In vitro and in vivo flow characteristics of glaucoma drainage implants. Ophthalmology 1995;102:894-904.

23 Susanna R, Nicolela MT, Takahashi WY. Mitomycin C as adjunctive therapy with glaucoma implant surgery. $O p h$ thalmic Surg 1994;25:458-62.

24 Perkins TW, Cardakli UF, Eisele JR, et al. Adjunctive mitomycin C in Molteno implant surgery. Ophthalmology 1995; 102:91-7.

25 Lee D, Shin DH, Birt CM, et al. The effect of adjunctive mitomycin C in Molteno implant surgery. Ophthalmology 1997;104:2126-35.

26 Minckler DS, Heuer DK, Hasty B, et al. Clinical experiences with the single plate Molteno implant in complicated glaucomas. Ophthalmology 1988;95:1181-8.

27 Price FW, Wellemeyer M. Long-term results of Molteno implants. Ophthalmic Surg 1995;26:130-5.

28 Law SK, Kalenak JW, Connor Jr TB, et al. Retinal complications after aqueous shunt surgical procedures for glaucoma. Arch Ophthalmol 1996;114:1473-80. 